\title{
AKSESIBILITAS JEMBATAN PENYEBERANGAN ORANG (JPO) BAGI PENYANDANG DIFABEL DI KOTA BANDA ACEH MENURUT PERSEPSI MASYARAKAT
}

\author{
M. Isya ${ }^{1)}$, Irin Caisarina ${ }^{1)}$, Etty Herawaty ${ }^{2)}$ \\ ${ }^{1)}$ Fakultas Teknik Universitas Syiah Kuala ${ }^{2)}$ Alumni Magister Teknik Sipil PPs \\ Universitas Syiah Kuala Banda Aceh \\ Email:misftunsyiah@yahoo.com,irene1805@yahoo.com,etty_hera@yahoo.com)
}

\begin{abstract}
Abstrak
Transportasi merupakan kegiatan memindahkan orang/barang dari suatu tempat ke tempat lain. Fasilitas yang digunakan termasuk sarana dan prasarana transportasi yang fungsinya harus dapat digunakan oleh semua orang tanpa kecuali penyandang difabel. Untuk itu, studi tentang penyediaan kelengkapan prasarana untuk penyandang difabel dirasa perlu untuk dilakukan. Tujuan penelitian ini adalah untuk mengidentifikasi sejauh mana kelengkapan jembatan penyeberangan orang yang mudah digunakan oleh penyandang difabel serta mengetahui kondisi dan alternatif penanganan aksesibilitas jembatan penyeberangan orang terhadap penyandang difabel berdasarkan persepsi masyarakat dan instansi terkait. Penelitian ini dilaksanakan dengan melakukan pengamatan secara langsung di lapangan, membagikan kuesioner untuk mengetahui persepsi responden dan wawancara kepada para key informant. Pengolahan dan analisis data dilakukan secara deskriptif. Data hasil kuesioner diolah menggunakan skala likert. Hasil penelitian menunjukkan bahwa jembatan penyeberangan orang di Jalan Tgk. Daud Beureueh dalam kondisi tidak baik bagi penyandang difabel. Hasil kajian juga menyarankan agar pada masa yang akan datang agar pengambil keputusan sudah seharusnya mengakomodasi kebutuhan akan para difabel untuk dapat menggunakan jembatan penyeberangan secara mandiri dengan memberikan akses sebaik mungkin dan melengkapi fasilitas.
\end{abstract}

Kata-kata Kunci: Jembatan Penyeberangan Orang, Difabel, Aksesibilitas, Jalan Tgk. Daud Beureueh, Persepsi.

\section{Pendahuluan}

Transportasi merupakan kegiatan memindahkan orang/barang dari suatu tempat ke tempat lain. Fasilitas yang digunakan termasuk sarana dan prasarana transportasi yang fungsinya harus dapat digunakan oleh semua orang tanpa kecuali penyandang difabel. Difabel termasuk didalamnya lansia, wanita hamil, anak-anak, penderita sakit, orang tua dengan anak dan penyandang disabilitas.

Data Dinas Sosial Provinsi Aceh menyatakan bahwa jumlah penyandang disabilitas di Aceh sampai tahun 2013 sekitar 61.000 orang. Jumlah tersebut dari tahun ke tahun mengalami kenaikan sekitar 3,4\%. Jika dibanding angka nasional yang mencapai $2,9 \%$, jumlah penyandang disabilitas di Aceh relatif kecil, hanya sekitar 1,2\% dari total penduduk (medan bisnis daily, 2013).

Dari pengamatan visual, aksesibilitas bagi penyandang difabel pada prasarana transportasi di kota Banda Aceh masih rendah. Untuk itu perlu dilakukan kajian mengenai pentingnya prasarana transportasi khususnya jalan raya di perkotaan bagi penyandang difabel. Lokasi penelitian yang dipilih adalah 
di kawasan Jalan Tgk. Daud Beureueh Banda Aceh dimulai dari depan Kantor BPOM sampai ke Simpang Jamboe Tape. Tujuan dari penelitian ini adalah mengidentifikasi sejauhmana kelengkapan prasarana jalan raya yang dapat dan mudah digunakan oleh penyandang difabel berdasarkan persepsi masyarakat dan memberikan solusi penanganan pada masa yang akan datang.

\section{Tinjauan Kepustakaan}

Mujimin (2007) menyatakan difabel merupakan istilah yang diindonesiakan dari diffable (people with different abilities). Istilah difabel memberi peluang untuk memperhatikan masyarakat dengan kondisi berbeda sehingga istilah difabel juga mencakup orang tua lanjut usia (lansia), wanita hamil, dan kelompok lainnya yang memiliki kemampuan berbeda dengan kelompok masyarakat umumnya.

Berdasarkan Peraturan Menteri Pekerjaan Umum dalam Departemen PU (2006), didefinikan bahwa aksesibilitas adalah kemudahan yang disediakan bagi semua orang termasuk penyandang cacat dan lansia guna mewujudkan kesamaan kesempatan dalam segala aspek kehidupan dan penghidupan. Prasarana aksesibilitas di jalan umum didasarkan pada Peraturan Pemerintah No.43/Tahun 1998 Pasal 13 tentang upaya peningkatan kesejahteraan sosial penyandang cacat (Sekretariat Negara, 1998) adalah:

1. Akses ke, dan dari jalan umum;

2. Akses ke tempat pemberhentian bis/kendaraan;

3. Jembatan penyeberangan;

4. Jalur penyeberangan bagi pejalan kaki;

5. Tempat parkir dan naik/turun penumpang;

6. Tempat pemberhentian kendaraan umum;

7. Tanda/rambu-rambu lalu lintas dan atau marka jalan;

8. Trotoar bagi pejalan kaki/pemakai kursi roda;

9. Terowongan penyeberangan.

Asas fasilitas dan aksesibilitas menurut Departemen PU (2006), mengemukakan bahwa setiap fasilitas publik harus memenuhi 4 asas yaitu: keselamatan, kemudahan, kegunaan dan kemandirian. Menurut tata cara perencanaan jembatan penyeberangan untuk pejalan kaki di perkotaan dalam Dirjen Bina Marga (1995), disebutkan bahwa jembatan penyeberangan pejalan kaki adalah jembatan yang hanya diperuntukan bagi lalu lintas pejalan kaki yang melintas di atas jalan raya atau jalan kereta api. Berikut beberapa syarat yang harus dipenuhi, adalah:

1. Ketinggian bagian bawah jembatan penyeberangan orang (JPO):

a. Jalan raya: 4,6 meter (tidak dilalui bus tingkat)/5,1 meter (dilalui bus tingkat).

b. Jalur kereta: 6,5 meter.

2. Tangga penghubung jembatan penyeberangan harus mengikuti ketentuan sebagai berikut:

a. Tangga direncanakan untuk memikul beban hidup nominal sebesar $5 \mathrm{kPa}$.

b. Lebar bebas untuk jalur pejalan kaki minimum adalah $2 \mathrm{~m}$.

c. Perencanaan dimensi tanjakan dan anjakan harus mengacu pada ketentuan:

- Tinggi anjakan minimum $15 \mathrm{~cm}$ dan maksimum $21,5 \mathrm{~cm}$.

Aksesibilitas Jembatan Penyeberangan Orang Jompo (JPO) Bagi Penyandang Difabel di Kota Banda Aceh Menurut Persepsi Masyarakat - M.Isya, Irin Caisarina, Etty 
- Lebar anjakan minimum 21,5 cm dan maksimum adalah 30,5 cm.

- Jumlah tanjakan dan injakan ditetapkan berdasarkan tinggi lantai jembatan yang direncanakan.

\section{Metode Penelitian}

Tahapan-tahapan yang dilakukan dalam penelitian ini dapat digambarkan dalam suatu bentuk diagram alir. Diagram alir dari sistematika penelitian ini dapat ditunjukkan pada Gambar 1.

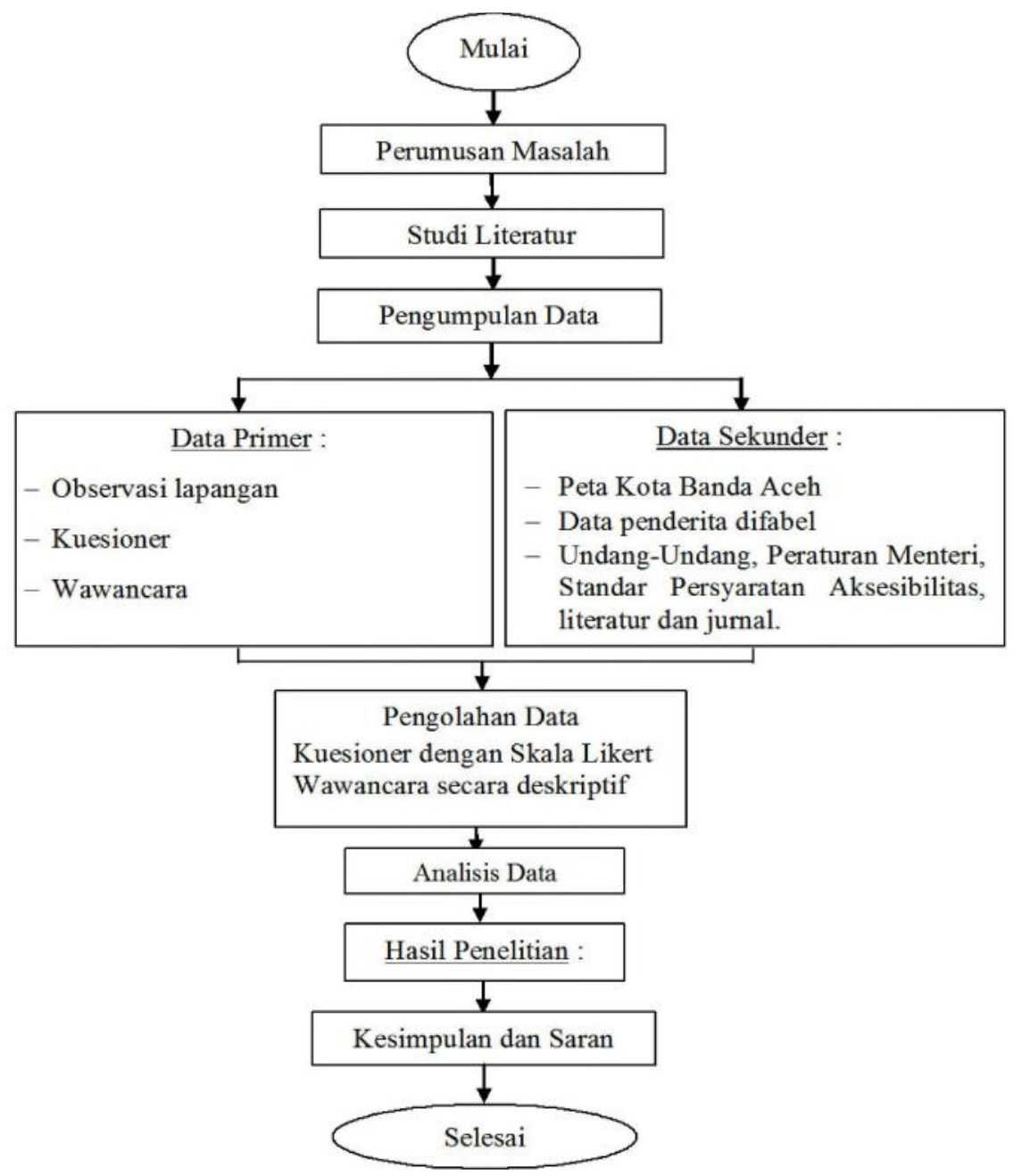

Gambar 1. Diagram Alir Penelitian

\section{Hasil dan Pembahasan}

\subsection{Kondisi Eksisting Jembatan Penyeberangan Orang (JPO)}

Penelitian ini berlokasi di Jalan Tgk. Daud Beureueh tepatnya dari depan Kantor Balai Pusat Obat dan Makanan sampai ke Simpang Jamboe Tape. Objek yang diteliti adalah jembatan penyeberangan orang. Adapun Kondisi eksisting Jembatan Penyeberangan Orang (JPO) ditunjukkan pada Tabel 1 sebagai berikut: 
Tabel 1. Kondisi eksisting JPO

\begin{tabular}{|c|c|c|c|c|}
\hline No. & Bagian yang diamati & $\begin{array}{l}\text { Tata Cara Perencanaan } \\
\text { Jembatan Penyeberangan } \\
\text { untuk Pejalan Kaki di } \\
\text { Perkotaan No. 027/T/Bt/1995 }\end{array}$ & $\begin{array}{l}\text { Memenuhi } \\
\text { syarat/tidak } \\
\text { memenuhi }\end{array}$ & $\begin{array}{l}\text { Kondisi } \\
\text { eksisting }\end{array}$ \\
\hline \multicolumn{5}{|c|}{ Jembatan Penyeberangan Orang di depan RSU ZA Lama } \\
\hline 1. & $\begin{array}{l}\text { - Ketinggian bagian } \\
\text { bawah JPO }\end{array}$ & $4,6 \mathrm{~m}$ & $\mathrm{x}$ & $6,30 \mathrm{~m}$ \\
\hline 2. & $\begin{array}{l}\text { - Lebar bebas untuk } \\
\text { jalur pejalan kaki }\end{array}$ & Min $2 \mathrm{~m}$ & $\sqrt{ }$ & $2,41 \mathrm{~m}$ \\
\hline 3. & - Tinggi anjakan tangga & Min $15 \mathrm{~cm}$ dan maks $21,5 \mathrm{~cm}$ & $\sqrt{ }$ & $19 \mathrm{~cm}$ \\
\hline 4. & - Lebar anjakan tangga & $\begin{array}{l}\text { Min } 21,5 \mathrm{~cm} \text { dan maks } 30,5 \\
\mathrm{~cm}\end{array}$ & $\sqrt{ }$ & $30 \mathrm{~cm}$ \\
\hline 5 . & $\begin{array}{l}\text { - Peletakan tangga dan } \\
\text { kepala jembatan }\end{array}$ & $\begin{array}{l}\text { Diletakkan di luar jalur } \\
\text { trotoar }\end{array}$ & $\mathrm{x}$ & $\begin{array}{l}\text { Dijalur } \\
\text { trotoar }\end{array}$ \\
\hline 6. & $\begin{array}{l}\text { - Peletakkan pilar } \\
\text { tengah jembatan }\end{array}$ & Di tengah median & $\sqrt{ }$ & sesuai \\
\hline \multicolumn{5}{|c|}{ Jembatan Penyeberangan Orang di depan Wilayatul Hisbah } \\
\hline 1. & $\begin{array}{l}\text { Keting gian bagian } \\
\text { bawah JPO }\end{array}$ & $4,6 \mathrm{~m}$ & $\mathrm{x}$ & $6,30 \mathrm{~m}$ \\
\hline 2. & $\begin{array}{l}\text { - Lebar bebas untuk } \\
\text { jalur pejalan kaki }\end{array}$ & Min $2 \mathrm{~m}$ & $\mathrm{x}$ & $1,2 \mathrm{~m}$ \\
\hline 3. & - Tinggi anjakan tangga & Min $15 \mathrm{~cm}$ dan maks $21,5 \mathrm{~cm}$ & $\sqrt{ }$ & $21 \mathrm{~cm}$ \\
\hline 4. & - Lebar anjakan tangga & $\begin{array}{l}\text { Min } 21,5 \mathrm{~cm} \text { dan maks } 30,5 \\
\mathrm{~cm}\end{array}$ & $\sqrt{ }$ & $25 \mathrm{~cm}$ \\
\hline 5. & $\begin{array}{l}\text { Peletakan tangga dan } \\
\text { kepala jembatan }\end{array}$ & $\begin{array}{l}\text { Diletakkan di luar jalur } \\
\text { trotoar }\end{array}$ & $\sqrt{ }$ & sesuai \\
\hline 6. & $\begin{array}{l}\text { - Peletakkan pilar } \\
\text { tengah jembatan }\end{array}$ & Di tengah median & $\sqrt{ }$ & sesuai \\
\hline
\end{tabular}

Sumber: Pengamatan Lapangan, 2014

Keterangan checklist:

$\begin{array}{ll}\sqrt{ } & : \text { memenuhi syarat } \\ \mathrm{X} & \text { : tidak memenuhi syarat }\end{array}$

Berdasarkan Tabel 1 di atas terlihat bahwa JPO tidak memenuhi Tata Cara Perencanaan Jembatan Penyeberangan untuk Pejalan Kaki di Perkotaan No. 027/T/Bt/1995. Namun yang memenuhi persyaratan hanya pada tinggi pijakan tangga, lebar pijakan tangga dan peletakkan pilar tengah jembatan.

Pengamatan di lapangan, jembatan penyeberangan orang yang berada di depan Rumah Sakit lama dr. Zainoel Abidin dan di depan kantor Wilayatul Hisbah dalam kondisi tidak layak untuk digunakan baik untuk orang normal ataupun penyandang difabel. Hal ini terlihat dari ketinggin bagian bawah jembatan dengan jalan, kondisi material jembatan mengalami korosi, atap jembatan bocor, serta pijakan anak tangga yang tanpa pelindung bawah sehingga membahayakan penggunanya. 
Berdasarkan tata Cara Perencanaan menurut Dirjen Bina Marga (1995), tinggi ideal jembatan penyeberangan orang adalah 4,6 $\mathrm{m}$ apabila tidak dilalui bus tingkat dan 5,1 m apabila dilalui bus tingkat serta perletakkan kepala jembatan berada diluar jalur trotoar. Kondisi di lapangan tinggi jembatan penyeberangan orang terlalu tinggi yaitu $6,10 \mathrm{~m}$ dan kepala jembatan berada di jalur trotoar sehingga hal itu sangat tidak sesuai dengan standar yang berlaku dan sirkulasi pejalan kaki menjadi tidak lancar serta tidak aman. keadaan tersebut mengakibatkan para pejalan kaki lebih memilih tidak mempergunakan jembatan penyeberangan yang ada dan lebih memilih menyeberang langsung di jalan. Untuk lebih jelasnya dapat di lihat pada Gambar 2.
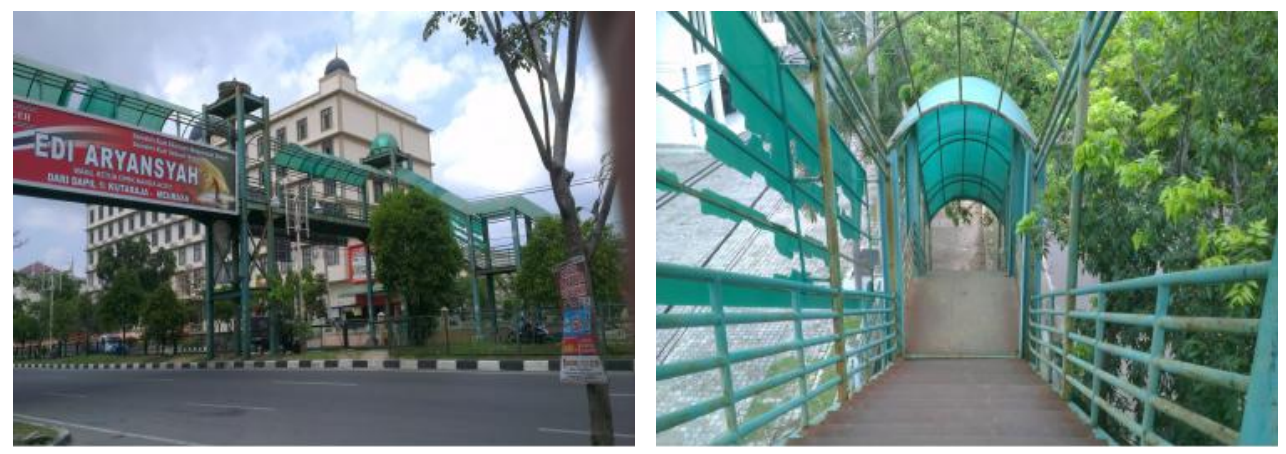

Gambar 2. Kondisi Eksisting JPO

\subsection{Pengolahan data Kuesioner}

\subsubsection{Reliabilitas dan Validitas}

Pengujian reliabilitas mengacu pada metode Arikunto (2010), menggunakan software SPSS 16.0. Hasil pengujian reliabilitas dapat dilihat pada Tabel 2.

Tabel 2. Hasil pengujian reliabilitas

\begin{tabular}{|c|c|c|c|c|}
\hline Bagian & No.Pertanyaan & $\begin{array}{r}\text { Koefisien } \\
\text { Cronbach's Alpha }\end{array}$ & Nilai Alpha & Hasil \\
\hline \multicolumn{5}{|c|}{ Jembatan Penyeberangan Orang (JPO) } \\
\hline A. & $1-8$ & 0,943 & & Reliabel \\
\hline B. & $1-5$ & 0,910 & \multirow{2}{*}{0,6} & Reliabel \\
\hline C. & $1-2$ & 0,784 & & Reliabel \\
\hline
\end{tabular}

Tabel 2 di atas dapat dilihat semua item pertanyaan dari 3 (tiga) kategori A, $\mathrm{B}$, dan $\mathrm{C}$ untuk prasarana jalan raya yang diteliti menghasilkan nilai Cronbach's Alpha $>0,60$.

Pengujian validitas menggunakan software SPSS 16.0. Jumlah responden untuk uji coba kuesioner yaitu 30 (tiga puluh) sampel, sehingga df $=30-2=28$. Jadi nilai $\mathrm{r}$ (product moment) dengan tingkat kesalahan $5 \%=0,374$. Hasil pengujian validitas untuk tiga bagian pertanyaan diperoleh $r$ hitung lebih besar 
dari $r$ tabel, maka dapat disimpulkan bahwa semua pertanyaan tersebut valid, jadi dapat digunakan.

\subsubsection{Persepsi Masyarakat terhadap Fungsi Fasilitas JPO}

Persepsi masyarakat terhadap fungsi fasilitas JPO di kawasan Jalan Tgk. Daud Beureueh terhadap dua kelompok responden (masyarakat umum dan penyandang difabel) yang masing jumlah responden adalah 50 orang dan 107 orang. Berikut penjelasan lengkapnya.

Tabel 3 Fungsi Fasilitas JPO

\begin{tabular}{|l|l|c|l|l|l|}
\hline \multirow{2}{*}{ No } & \multicolumn{1}{|c|}{ Pertanyaan } & \multicolumn{2}{c|}{$\begin{array}{c}\text { Masyarakat } \\
\text { umum }\end{array}$} & \multicolumn{2}{c|}{$\begin{array}{c}\text { Penyandang } \\
\text { difabel }\end{array}$} \\
\cline { 3 - 6 } & \multicolumn{1}{|c|}{$\begin{array}{c}\text { Total } \\
\text { skor }\end{array}$} & Kategori & $\begin{array}{l}\text { Total } \\
\text { skor }\end{array}$ & Kategori \\
\hline 1. & $\begin{array}{l}\text { Ketersediaan fasilitas prasarana } \\
\text { Dalan raya di kawasan Jln. Tgk. }\end{array}$ & 162 & Netral & 275 & $\begin{array}{l}\text { Tidak } \\
\text { baik }\end{array}$ \\
\hline 2. & Segi keamanan & 129 & $\begin{array}{l}\text { Tidak } \\
\text { baik }\end{array}$ & 217 & $\begin{array}{l}\text { Tidak } \\
\text { baik }\end{array}$ \\
\hline 3. & Segi keselamatan & 126 & $\begin{array}{l}\text { Tidak } \\
\text { baik }\end{array}$ & 202 & $\begin{array}{l}\text { Tidak } \\
\text { baik }\end{array}$ \\
\hline 4. & $\begin{array}{l}\text { Segi kemudahan untuk mencapai } \\
\text { tempat tujuan anda }\end{array}$ & 125 & $\begin{array}{l}\text { Tidak } \\
\text { baik }\end{array}$ & 174 & $\begin{array}{l}\text { Sangat } \\
\text { tidak } \\
\text { baik }\end{array}$ \\
\hline 5. & Segi kegunaan & 124 & $\begin{array}{l}\text { Tidak } \\
\text { baik }\end{array}$ & 265 & Netral \\
\hline 6. & Segi kenyamanan & 118 & $\begin{array}{l}\text { Tidak } \\
\text { baik }\end{array}$ & 166 & $\begin{array}{l}\text { Sangat } \\
\text { tidak } \\
\text { baik }\end{array}$ \\
\hline 7. & Segi kemandirian & 115 & $\begin{array}{l}\text { Tidak } \\
\text { baik }\end{array}$ & 165 & $\begin{array}{l}\text { Sangat } \\
\text { tidak } \\
\text { baik }\end{array}$ \\
\hline 8. & $\begin{array}{l}\text { Segi aksesibilitas jalur } \\
\text { penyandang cacat }\end{array}$ & 86 & $\begin{array}{l}\text { Sangat } \\
\text { tidak } \\
\text { baik }\end{array}$ & 117 & $\begin{array}{l}\text { Sangat } \\
\text { tidak } \\
\text { baik }\end{array}$ \\
\hline
\end{tabular}

Berdasarkan Tabel 3. di atas terkait fungsi fasilitas jembatan penyeberangan orang, masyarakat umum menyatakan netral terkait ketersediaan fasilitas jembatan penyeberangan orang dengan skor 162 sedangkan penyandang difabel menyatakan tidak baik. Segi aksesibilitas jalur penyandang cacat masyarakat umum dan penyandang difabel menyatakan pendapat sangat tidak baik terhadap fungsi fasilitas JPO.

Peraturan Menteri Pekerjaan Umum N0.30/PRT/M/2006 terkait Asas fasilitas dan aksesibilitas dan ketentuan teknik dari geometrik jalan tidak terlihat dilokasi penelitian. Berdasarkan Mashuri dan Sigit mengutip dari Kurniawan (2004) menyebutkan beberapa faktor yang menjadi pertimbangan agar jembatan penyeberangan orang memberikan manfaat maksimal bagi pejalan kaki seperti: memberikan tingkat kenyamanan pejalan kaki yang optimal seperti jarak tempuh, faktor kelandaian dan serta rambu-rambu petunjuk pejalan kaki sehingga memudahkan pejalan kaki untuk melintas. Kenyataan di lapangan jembatan penyeberangan orang tidak memberikan manfaat bagi pejalan kaki dikarenakan JPO terlalu tinggi dan fasilitasnya dalam keadaan rusak. 
Berdasarkan hasil wawancara dari key informant, fasilitas JPO pada Jalan Tgk Daud Beureueh direncanakan, dibangun dan dirawat oleh Dinas Perhubungan Provinsi Aceh. Mengenai ketersediaan JPO pada lokasi penelitian key informant mengatakan sudah cukup, dikarenakan kebutuhan masyarakat akan JPO belum mendesak. JPO yang berada di depan rumah sakit lama Zainoel Abidin di peruntukkan bagi masyarakat yang berada dan akan menuju rumah sakit lama Zainoel Abidin atau ke Masjid Agung Al- Makmur sedangkan yang berada di depan Kantor Wilayatul Hisbah diperuntukkan bagi siswa sekolah. Hasil pengamatan di lapangan kedua JPO tersebut jarang ada yang mempergunakan atau dapat dikatakkan tidak ada yang menggunakan.

\subsubsection{Persyaratan Aksesibilitas JPO}

Persepsi masyarakat terhadap persyaratan aksesibilitas JPO di kawasan Jalan Tgk. Daud Beureueh terhadap dua kelompok responden (masyarakat umum dan penyandang difabel) dengan jumlah responden adalah 50 orang dan 107 orang. Berikut penjelasan lengkapnya ditampilakan pada Tabel 4.

Tabel 4 Persyaratan Aksesibilitas Prasarana Jalan Raya

\begin{tabular}{|l|l|c|l|c|l|}
\hline \multirow{2}{*}{ No } & \multicolumn{1}{|c|}{ Pertanyaan } & \multicolumn{2}{|c|}{$\begin{array}{c}\text { Masyarakat } \\
\text { umum }\end{array}$} & \multicolumn{2}{|c|}{$\begin{array}{c}\text { Penyandang } \\
\text { difabel }\end{array}$} \\
\cline { 3 - 6 } & $\begin{array}{c}\text { Total } \\
\text { skor }\end{array}$ & Kategori & $\begin{array}{l}\text { Total } \\
\text { skor }\end{array}$ & Kategori \\
\hline 1. & $\begin{array}{l}\text { Kelandaian trotoar di kawasan } \\
\text { Jalan Tgk.daud Beureueh }\end{array}$ & 126 & $\begin{array}{l}\text { Tidak } \\
\text { baik }\end{array}$ & 201 & $\begin{array}{l}\text { Tidak } \\
\text { baik }\end{array}$ \\
\hline 2. & $\begin{array}{l}\text { Persyaratan bahan trotoar } \\
\text { ditinjau dari jenis tekstur bahan } \\
\text { ubin }\end{array}$ & 142 & Netral & 201 & $\begin{array}{l}\text { Tidak } \\
\text { baik }\end{array}$ \\
\hline 3. & $\begin{array}{l}\text { Lebar trotoar yang tersedia di } \\
\text { kawasan Jalan Tgk.daud } \\
\text { Beureueh }\end{array}$ & 168 & Netral & 302 & Netral \\
\hline 4. & $\begin{array}{l}\text { Kemudahan anda untuk } \\
\text { mengakses halte }\end{array}$ & 155 & Netral & 214 & $\begin{array}{l}\text { Tidak } \\
\text { baik }\end{array}$ \\
\hline 5. & $\begin{array}{l}\text { Ukuran jembatan penyeberangan } \\
\text { orang (tinggi, lebar, jumlah anak } \\
\text { tangga) }\end{array}$ & 125 & $\begin{array}{l}\text { Tidak } \\
\text { baik }\end{array}$ & 150 & $\begin{array}{l}\text { Tidak } \\
\text { baik }\end{array}$ \\
\hline
\end{tabular}

Berdasarkan Tabel 4 diketahui hasil penyebaran kuesioner terkait persyaratan aksesibilitas JPO, responden masyarakat umum dan penyandang difabel menyatakan ukuran jembatan penyeberangan orang (tinggi, lebar, dan jumlah anak tangga) tidak baik.

Ditinjau dari ukuran JPO (tinggi, lebar, jumlah anak tangga) menurut tata cara perencanaan jembatan penyeberangan untuk pejalan kaki di perkotaan No. 027/T/Bt/1995 (Dirjen Bina Marga, 1995) bahwa standar ketinggian bagian bawah jembatan penyeberangan orang (JPO) yaitu: Jalan raya: 4,6 meter (tidak dilalui bus tingkat)/5,1 meter (dilalui bus tingkat) dan Jalur kereta: 6,5 meter. Kenyataan di lapangan, tinggi JPO adalah $6,30 \mathrm{~m}$ melebihi tinggi JPO yang tidak 
dilalui bus tingkat yaitu 4,6 m. hal ini didukung dengan hasil sebaran kuesioner yang menyatakan ukuran JPO tidak baik.

\subsubsection{Solusi Fungsi Aksesibilitas JPO}

Berdasarkan dua kategori pertanyaan terkait dengan fungsi aksesibilitas trotoar dan persyaratan aksesibilitas trotoar, penulis juga mengajukan pertanyaan terkait dengan solusi fungsi aksesibilitas prasarana jalan raya. Berikut pendapat masyarakat umum, penyandang difabel dan penyandang disabilitas ditunjukkan Tabel 5 sebagai berikut.

Tabel 5 Solusi Fungsi Aksesibilitas Prasarana Jalan Raya (Trotoar)

\begin{tabular}{|l|l|l|l|l|l|}
\hline \multirow{2}{*}{ No } & \multicolumn{1}{|c|}{ Pertanyaan } & \multicolumn{2}{c|}{$\begin{array}{c}\text { Masyarakat } \\
\text { umum }\end{array}$} & \multicolumn{2}{c|}{$\begin{array}{c}\text { Penyandang } \\
\text { difabel }\end{array}$} \\
\cline { 3 - 6 } & $\begin{array}{l}\text { Total } \\
\text { skor }\end{array}$ & Kategori & $\begin{array}{l}\text { Total } \\
\text { skor }\end{array}$ & Kategori \\
\hline 1. & $\begin{array}{l}\text { Prasarana jalan raya yang baik } \\
\text { harus dapat menampung setiap } \\
\text { kegiatan pejalan kaki dengan } \\
\text { lancar dan aman }\end{array}$ & 187 & Setuju & 403 & Setuju \\
\hline 2. & $\begin{array}{l}\text { Fasilitas prasarana jalan raya } \\
\text { dari segi kelayakan kondisi fisik } \\
\text { (bahan) dapat digunakan oleh } \\
\text { semua orang }\end{array}$ & 197 & Setuju & 444 & $\begin{array}{l}\text { Sangat } \\
\text { setuju }\end{array}$ \\
\hline
\end{tabular}

Berdasarkan Tabel 5 diketahui bahwa responden menyatakan pendapat setuju terkait JPO yang baik harus dapat menampung kegiatan penjalan kaki dengan lancar dan aman. Ditinjau dari fasilitas JPO dari segi kelayakan fisik (bahan) dapat digunakan oleh semua orang responden juga menyatakan setuju.

Berdasarkan Peraturan Menteri Pekerjaan Umum N0.30/PRT/M/2006 (Departemen PU, 2006), yaitu harus memenuhi 4 (empat) asas diantaranya: keselamatan, kemudahan, kegunaan dan kemandirian dapat terpenuhi dengan kelayakan fisik (bahan) yang dipergunakan pada fasilitas prasarana jalan raya. Sehingga PP Nomor 43 Tahun 1998 tentang upaya peningkatan kesejahteraan sosial penyandang cacat dapat terpenuhi. Termasuk pula kegiatan penjalan kaki menjadi lancar dan aman.

\section{Kesimpulan dan Saran}

\subsection{Kesimpulan}

Berdasarkan hasil penelitian dapat diambil beberapa kesimpulan sebagai berikut:

1. Kondisi eksisting jembatan penyeberangan orang di Jalan Tgk. Daud Beureueh tidak sesuai dengan tata cara perencanaan jembatan penyeberangan.

2. Peraturan Menteri Pekerjaan Umum N0.30/PRT/M/2006 tentang Pedoman Teknis Fasilitas dan Aksesibilitas pada Bangunan Gedung dan Lingkungan belum diterapkan.

3. Tingkat keamanan dan kenyamanan di lokasi penelitian buruk.

4. Segi aksesibilitas jalur penyandang cacat tidak terlihat pada jembatan penyeberangan orang yang berada di Jalan Tgk. Daud Beureueh. 
5. Responden menyatakan pendapat setuju terkait jembatan penyeberangan orang yang baik harus dapat menampung kegiatan penjalan kaki dengan lancar dan aman, dan dapat digunakan oleh semua orang.

\subsection{Saran}

Saran-saran yang dapat diberikan sebagai bentuk rekomendasi kepada pihak terkait adalah sebagai berikut:

1. Perlu menjalankan pamanah dari Peraturan Menteri Pekerjaan Umum N0.30/PRT/M/2006, agar ketersediaan fasilitas publik yang ramah dan aksesibel bagi kaum difabel dapat terpenuhi.

2. Perlu dilibatkan Dinas Sosial selaku yang melindungi penyandang difabel dalam perencanaan dan pengawasan terkait aksesibilitas pada bangunan gedung dan jalan umum seperti adanya Qanun khusus bagi Penyandang Cacat.

3. Perlu adanya peletakkan jembatan penyeberangan orang di depan Rumah Sakit Umum Dr. Zainoel Abidin Baru.

\section{Daftar Kepustakaan}

Arikunto, S., 2010, Prosedur Penelitian, Penerbit Rineka Cipta, Jakarta.

Direktorat Jenderal Bina Marga, 1995, Tata Cara Perencanaan Jembatan Penyeberangan untuk Pejalan Kaki di Perkotaan No.027/T/BT/1995, Direktur Bina Teknik, Jakarta.

Direktorat Jenderal Bina Marga, 1999, Pedoman Teknik Persyaratan Aksesibilitas pada Jalan Umum No.022/T/BM/1999, PT. Mediatama Saptakarya (PT.Medisa), Jakarta.

Departemen Pekerjaan Umum, 2006, Peraturan Menteri Pekerjaan Umum Nomor: 30/PRT/M/2006 Tentang Pedoman Teknis Fasilitas dan Aksesibilitas pada Bangunan Gedung dan Lingkungan, Jakarta.

Medanbisnisdaily, 2013, Pemko Banda Aceh sediakan Fasus bagi Penyandang Disabilitas diakses 18 Oktober 2013.

http://www.medanbisnisdaily.com/news/read/2013/07/03/38124/pemko Banda Aceh sediakan fasus bagi penyandang disabilitas/\#.UmCxj4H6fTU.

Mujimin, W. M., 2007, Dinamika Pendidikan (Penyediaan Fasilitas Publik yang Manusiawi Bagi Aksesibilitas Difabel), No.1/Th.XIV/Mei 2007, Universitas Negeri Yogyakarta.

Nazir, M., 2011, Metode Penelitian, Penerbit Ghalia Indonesia, Bogor.

Sekretariat Negara, 1998, Peraturan Pemerintah Republik Indonesia Nomor 43 Tahun 1998, Tentang Upaya Peningkatan Kesejahteraan Sosial Penyandang Cacat, Jakarta. 